Contributors: $\mathrm{CB}$, the principal investigator, initiated the study; collected data; documented and designed the study; drafted the hypothesis; and wrote the paper. PB had the original idea for the hypothesis and coordinated the study. MS, the principal motivator of the study, participated in designing and editing the paper. AJS performed all the statistical analysis of the data and created the graphs. BJW helped to collect data and tried to correlate the changes in animal behaviour with the changes in nature.

Funding: No special funding

Competing interests: None declared.

1 Raison CL, Klin HM, Steckler M. The moon and madness reconsidered. JAffect Disord 1999;53:99-106.

2 Thakur CP, Sharma D. Full moon and crime. BMJ 1984;289:1789-91.

3 Soyman P, Holdstock TL. The influence of the sun, moon, climate and economic conditions on crisis incidence. J Clin Psychol 1980;36:884-93.
4 Sitar J. Chronobiology of human aggression. Cas Lek Cesk 1997;136: $174-80$

5 Ghiandoni G, Secli R, Rocchi MB, Ugolini G. Incidence of lunar position in the distribution of deliveries. A statistical analysis. Minerva Ginecol 1997;49:91-4.

6 Sitar J. The effect of the semilunar phase on an increase in traffic accidents. Cas Lek Cesk 1994;133:596-8.

7 Owen C, Tarantello C, Jones M, Tennant C. Lunar cycles and violent behaviour. Aust N Z J Psychiatry 1998;23:496-9.

8 DeCastro JM, Pearcey SM. Lunar rhythms of the meal and alcohol intake of humans. Physiol Behav 1995;57:439-44.

9 Sharfman M. Drug overdose and the full moon. Percept Mot Skills 1980;50:124-6.

10 Laverty WH, Kelly IW. Cyclical calendar and lunar patterns in automobile property accidents and injury accidents. Percept Mot Skills 1998;86:299pos.

11 Thompson DA, Adams SL. The full moon and ED patient volumes: unearthing a myth. Am J Emerg Med 1996;14:161-4.

12 Mikulecky M,Zemek R. Does the moon influence the predatory activity of mites? Experientia 1992;48:530-2.

\title{
Barking mad? Another lunatic hypothesis bites the dust
}

\author{
Simon Chapman, Stephen Morrell
}

\begin{abstract}
Objective To assess whether dog bites requiring hospital admission occur more at the full moon. Design Review of dates of admission for dog bites to accident and emergency departments, June 1997 to June 1998, compared with dates of the full moon.

Setting All public hospitals in Australia.

Main outcome measures Admissions for dog bites.

Results 12 peak clusters of admissions were unrelated to the time of the full moon.

Conclusion Dog bites are no more frequent on full moons than at any other time of the month. Sceptics rejoice.
\end{abstract}

\section{Introduction}

After publicity about the paper (by SC) on a randomised controlled trial to reduce dog bites, ${ }^{1}$ we were contacted by a farmer who asked: "Have you university types ever looked at whether dog bites happen more around the full moon? It's a well known fact that they do." Farmers are often storehouses of folkloric knowledge said to be derived from a rich tradition of empirical observation of, for example, sky colour and the weather ("red sky at night, shepherd's delight; red sky in the morning, shepherd's warning") or avoiding the wrath of bulls ("red rag to a bull")-so we leashed our scepticism and investigated.

The influence of the full moon remains one of the more resilient popular explanations of a wide range of mostly traumatic or bizarre events. There is a pale reflection of this in epidemiology-recall bias-where those affected by a rare or severe disease are more inclined to associate unrelated non-disease exposures to the disease. Although more women have been documented to menstruate around the full moon, ${ }^{2}$ research has generally failed to confirm any association between the full moon and the manifestation of psychiatric disorders or violence in psychiatric settings, ${ }^{3}{ }^{4}$ consultations for anxiety or depression in general practice, ${ }^{5}$ suicide and self poisoning, ${ }^{6} 7$ agitation among nursing home residents, ${ }^{8}$ car accidents, ${ }^{9}$ major trauma, ${ }^{10}$ or emergency department admissions. ${ }^{11}$

Weak associations have been reported between the full moon and the distribution of spontaneous full term deliveries, ${ }^{12}$ small increases in meal size and reduced alcohol consumption, ${ }^{13}$ unintentional poisonings,${ }^{14}$ absenteeism, ${ }^{15}$ aggression in Dade County, Florida ${ }^{16}$ and reports of crimes to three police stations in India between 1978 and 1982. The latter, in a nation devoted to astrology, was posited by the authors to be caused by "human tidal waves" caused by the gravitational pull of the moon. ${ }^{17}$

So it seems that humans are mostly impervious to putative effects of the full moon on mental health and behaviour. But what about our best friend, Phideau? Do howling dogs feel more inclined to bite humans during the full moon than at other times? Or are their barks worse than their bites when a human interrupts their canine arias? Such questions have dogged science for so long that they can no longer be ignawed.

\section{Methods}

We obtained from the National Injury Surveillance Unit 12 months of data on daily admissions for dog bites to all accident and emergency departments in public hospitals in Australia. We chose a year of data for analysis that would supply sufficient event numbers, both of dog bites and full moons, and would enable us to sniff out any seasonal variation in dog bite admissions. Age and sex of victims, but not perpetrators, were available. Daily admissions for 13 June 1997 to 12 June 1998 were plotted against the occurrence of a full moon. Mean daily admission numbers were analysed in relation to the presence or absence of a full moon, stratified by day of the week so that comparisons between full moon and non-full moon days were for the equivalent day of the week. Mean dog bite admissions during full moons occurring on, for example, a Monday were compared with dog bite admissions for all other Mondays.
Department of Public Health and Community

University of

Sydney, NSW 2006 Australia

Simon Chapman professor

Stephen Morrell senior research officer

Correspondence to: S Chapman simonc@health. usyd.edu.au

BMJ 2000;321:1561-3 


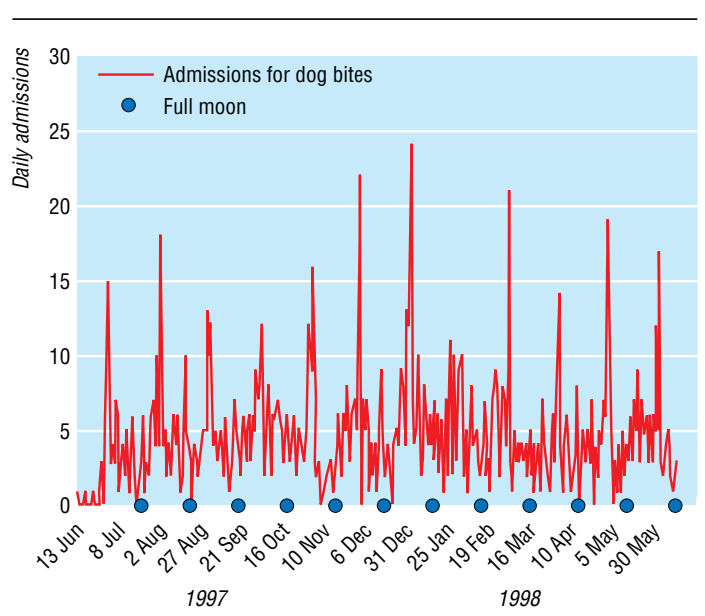

Fig 1 Daily admissions to hospital for dog bites, Australia, 13 June 1997 to 12 June 1998, and occurrence of full moon

\section{Results}

Altogether 1671 accident and emergency admissions for dog bites occurred during the study period (938 males, 733 females), representing an overall mean admission rate of 4.58 per day. Figure 1 shows 18 peak days (notionally $>10$ admissions/day), with the maximum peak centring on the New Year break (the highest peak (24) occurred on New Year's Day 1998). Full moons coincided with none of these peaks. The pattern was similar for female and male admissions.

Comparison of hospital admissions by day of the week is shown in figure 2. Mean daily admissions peaked at weekends ( 5.5 for Saturday, 5.6 for Sunday), and the number of admissions on weekdays ranged from 4.1 to 4.9 , forming overall a $\mathrm{U}$ shaped distribution from Sunday to Saturday with the trough occurring on Wednesday. On Sunday, Tuesday, and Thursday the mean number of admissions was substantially higher when a full moon occurred; on Monday, Wednesday, and Saturday the mean number

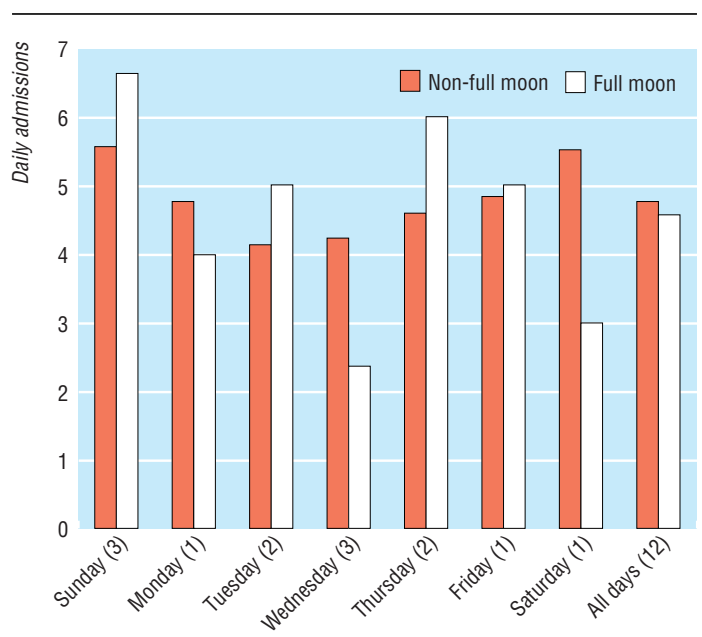

Fig 2 Mean daily admissions to hospital for dog bites, Australia, 13 June 1997 to 12 June 1998, by day of week (and with number of full moons occurring on each day during the study period), according to whether there was a full moon

\section{What is already known on this topic}

Farming folklore holds that dogs bite more at the time of full moons

The research literature on the effect of lunar phase on human behaviour has mostly shown no association

\section{What this study adds}

In Australia no association exists between lunar phase and dog bites requiring hospital admission

of admissions was substantially lower when a full moon occurred; and on Friday the mean was closely similar. This would be an expected result if dog bite admissions occurred randomly with respect to full moons. Overall, full moon days were associated with slightly lower mean admissions (4.6 compared with 4.8 per day).

\section{Discussion}

In Australia at least, no positive relation seems to exist between the full moon and dog bites severe enough for hospital treatment. Myers's critical appraisal of gravitational lunacy theory ${ }^{18}$ argued that, because tidal gravity fluxes are semidiurnal, with smaller diurnal and even smaller fortnightly components, there are no unique monthly gravitational components that would correspond to the period of the full moon. Also, the gravitational effects associated with the times of high tide are greater than those associated with moon phases. By applying this principle to absurd lengths, Myers suggested that any lunacy effects should occur twice each day with high tides and also should be more pronounced during the new moon and full moon (spring tides). Our data recorded time of bite, but investigation of Myers's hypothesis was muzzled by small numbers. As the plot of dog bite admissions and full moons clearly shows, more caution with dogs might be exercised over Christmas and especially at New Yearirrespective of the full moon.

We thank Malinda Steenkamp from the National Injury Surveillance Unit, Adelaide, for data.

Contributors: SC was bitten by the hypothesis, fetched the data, and reviewed the literature. SM analysed the data and inserted the worst puns. SC is guarantor.

Funding: No special funding.

Competing interests: Neither author owns a dog, but both quite like them. They are unscarred by bites.

1 Chapman S, Cornwall J, Righetti J, Sung L. Preventing dog bite in children: a randomised controlled trial of an educational intervention. BMJ 2000;320:1512-3.

2 Law SP. The regulation of menstrual cycle and its relationship to the moon. Acta Obstet Gynecol Scand 1986;65:45-8.

3 Raison CL, Klein HM, Steckler M. The moon and madness reconsidered. JAffect Disorders 1999;53:99-106.

4 Owen C, Tarantello C, Jones M, Tennant C. Lunar cycles and violent behaviour. Aust N Z J Psychiatry 1998;32:496-9.

5 Wilkinson G, Piccinelli M, Roberts S, Micciolo R, Fry J. Lunar cycle and consultations for anxiety and depression in general practice. Int J Soc Psychiatry 1997;43:29-34.

6 Mathew VM, Lindesay J, Shanmuganathan N, Eapen V. Attempted suicide and the lunar cycle. Psychological Reports 1991;68:927-30.

7 Buckley NA, Whyte IM, Dawson AH. There are days ... and moons. Selfpoisoning is not lunacy. Med J Aust 1993;159:786-9. 
8 Cohen-Mansfield J, Marx MS, Werner P. Full moon: does it influence agitated nursing home residents? J Clin Psychol 1989;45:611-4.

9 Laverty WH, Kelly IW. Cyclical calendar and lunar patterns in automobile property accidents and injury accidents. Perceptual \& Motor Skills 1998; 86:299-302.

10 Coates W, Jehle D, Cottington E. Trauma and the full moon: a waning theory. Ann Emerg Med 1989;18:763-5.

11 Thompson DA, Adams SL. The full moon and ED patient volumes: unearthing a myth. Am J Emerg Med 1996;14:161-4.

12 Ghiandoni G, Secli R, Rocchi MB, Ugolini G. Does lunar position influence the time of delivery? A statistical analysis. Eur J Obst Gynecol Reprod Biol 1998;77:47-50
13 De Castro JM, Pearcey SM. Lunar rhythms of the meal and alcohol intake of humans. Physiol Behav 1995;57:439-44.

14 Oderda GM, Klein-Schwartz W. Lunar cycle and poison center calls J Toxicol Clin Toxicol 1983;20:487-95.

15 Sands JM, Miller LE. Effects of moon phase and other temporal variables on absenteeism. Psychological Reports 1991;69:959-62.

16 Lieber AL. Human aggression and the lunar synodic cycle. J Clin Psychiatry 1978;39:385-92

17 Thakur CP, Sharma D. Full moon and crime, BMJ 1984;289: 1789-91.

18 Myers DE. Gravitational effects of the period of high tides and the new moon on lunacy.J Emerg Med 1995;13:529-32.

\section{Arabian nights-1001 tales of how pharmaceutical companies cater to the material needs of doctors: case report}

Ioannis A Giannakakis, John P A Ioannidis

\begin{abstract}
Objective To describe how pharmaceutical companies cater to the material needs of doctors.

Design Case report of memoirs.

Setting Facilities that have nothing to do with medicine, somewhere in the Arabian peninsula. Patient population Random sample of doctors. Interventions Promotion by the pharmaceutical industry.
\end{abstract}

Main outcome measures Short term outcomes were travel, pleasure, amusement, and gifts, and long term outcomes were the market share of specific companies.

Results Short term outcomes were heterogeneous, underlying the diversity of the means employed by the pharmaceutical industry to subvert, divert, and influence medical practice. Overall, 200 doctors were dressed in white gowns, a doctor in preventive medicine quoted Hippocrates in favour of smoking, a senior doctor became a poet, a doctor trying to understand the Methods section of a poster paper wondered whether he should have been sunbathing at the beach instead, and two women doctors were kidnapped by Bedouin warriors. Long term outcomes on the sales of the company drugs are pending but are likely to be most favourable.

Conclusions Eat, drink, be merry, and boost prescriptions.

\section{Introduction}

A warm night at the end of May, sky full of stars. I am floating supine on the Dead Sea. There is no need to move my arms or legs, no need to try to swim; just relax. The lifting power of the water is all that is needed; it's like floating in outer space without gravity. It feels good; I am content.

Could this experience be related to the way I practise medicine? Can it really influence and modify the way I diagnose and treat patients in my daily practice? Just follow the story.

\section{Case report}

I have not been alone for the past two days. I am staying at a luxury hotel with 200 other doctors from Greece. When we arrived we found flowers, avocados, pineapples, and white coats waiting for us in our rooms. We have been dressed in white since-not the medical coat, as you might think, but the traditional Arabian dress of a long gown with wide sleeves and an Arabian kerchief for the head. The women wear white silk dresses with fine embroidery.

I get out of the sea to take a shower. Salt is burning my senses. Time for food. There are tents at the beach. Under the tents, low tables are loaded with delicious Arabian dishes. Wine flows. We recline on pillows, as Bedouins do, and eat. Two hundred people eating, drinking, joking with each other, and having fun. When the dinner is over, many of my colleagues try smoking the traditional Ottoman pipe, with its pure tobacco burning at the bottom of a large glass bottle. "Down with the antismoking efforts! Life is short, said Hippocrates; enjoy it" exclaims one of our colleagues in preventive medicine, a passionate smoker, shaking the mouthpiece in his hand.

Exotic music surrounds us, first softly, then louder, more forceful, exuberant. This is a real beach party. Almost everyone is dancing, singing, drinking, and being merry. But here comes the greatest moment. A beautiful little khanum is presented, a girl of 18 , her perfect half naked body sparkling with jewels and semitransparent silk, her long dark hair shaking on her shoulders as she performs the belly dance to the sound of drums and flutes. A real temptation. Who can resist? Not the poor middle aged doctor who has lived all his life in a little Greek city in the north, with more rain than London and more fog than San Francisco. $\mathrm{He}$ works endless hours-harsh and with no enjoyment. $\mathrm{He}$ is one of the most successful practitioners, people say, judging from the bulk of his clientele, one of the best connected. He hasn't had a proper holiday for years. He is known to be terse, dedicated, and professional. And now, it seems that his destiny is in front of him, the little khanum. She is getting closer, rocking her body. At first he cannot move, his eyes are
Department of Hygiene and Epidemiology, University of Ioannina School of Medicine, Ioannina 45110, Greece

Ioannis A Giannakakis general practitioner

Clinical Trials and Evidence-Based Medicine Unit, University of

Ioannina School of Medicine

John P A Ioannidis chairman

Correspondence to: $\mathrm{J}$ P A Ioannidis jioannid@cc.uoi.gr

BMJ 2000;321:1563-4 